\title{
Long-Term Release of Iron-Cyanide Complexes from the Soils of a Manufactured Gas Plant Site
}

\author{
Magdalena Sut $^{1 *}$, Thomas Fischer ${ }^{2}$, Frank Repmann ${ }^{3}$, Thomas Raab ${ }^{1}$ \\ ${ }^{1}$ Department of Geopedology and Landscape Development, Brandenburg University of Technology Cottbus-Senftenberg, Cottbus, \\ Germany; ${ }^{2}$ Central Analytical Laboratory, Brandenburg University of Technology Cottbus-Senftenberg, Cottbus, Germany; ${ }^{3}$ De- \\ partment of Soil Protection and Recultivation, Brandenburg University of Technology Cottbus-Senftenberg, Cottbus, Germany. \\ Email: "sutmagda@tu-cottbus.de
}

Received August $2^{\text {nd }}, 2013$; revised September $5^{\text {th }}, 2013$; accepted October $3^{\text {rd }}, 2013$

Copyright (C) 2013 Magdalena Sut et al. This is an open access article distributed under the Creative Commons Attribution License, which permits unrestricted use, distribution, and reproduction in any medium, provided the original work is properly cited.

\begin{abstract}
Iron-cyanide (Fe-CN) complexes have been detected at Manufactured Gas Plant sites (MGP) worldwide. The risk of groundwater contamination depends mainly on the dissolution of ferric ferrocyanide. In order to design effective remediation strategies, it is relevant to understand the contaminant's fate and transport in soil, and to quantify and mathematically model a release rate. The release of iron-cyanide complexes from four contaminated soils, originating from the former MGP in Cottbus, has been studied by using a column experiment. Results indicated that long-term cyanide $(\mathrm{CN})$ release is governed by two phases: one readily dissolved and one strongly fixed. Different isotherm and kinetic equations were used to investigate the driving mechanisms for the ferric ferrocyanide release. Applying the isotherm equations assumed an approach by which two phases were separate in time, whereas the multiple first order equation considered simultaneous occurrence of both cyanide pools. Results indicated varying $\mathrm{CN}$ release rates according to the phase and soil. According to isotherm and kinetic models, the long-term iron cyanide release from the MGP soils is a complex phenomenon driven by various mechanisms parallely involving desorption, diffusion and transport processes. Phase I (rapid release) is presumably mainly constrained by the transport process of readily dissolved iron-cyanide complexes combined with desorption of $\mathrm{CN}$ bound to reactive heterogeneous surfaces that are in direct contact with the aqueous phase (outer-sphere complexation). Phase II (limited rate) is presumably driven by the diffusion controlled processes involving dissolution of precipitated ferric ferrocyanide from the mineral or inner-sphere complexation of ferricyanides. $\mathrm{CN}$ release rates in phase I and II were mainly influenced by the $\mathrm{pH}$, organic matter $(\mathrm{OM})$ and the total $\mathrm{CN}$ content. The cyanide release rates increased with increasing $\mathrm{pH}$, decreased with low initial $\mathrm{CN}$ concentration and were retarded by the increase in OM content.
\end{abstract}

Keywords: Prussian Blue; Elovich Equation; Freundlich Equation; Parabolic Diffusion Equation; Multiple First Order Equation

\section{Introduction}

Cyanide in the form of iron-cyanide (Fe-CN) complexes is a potentially toxic compound that once exposed to UV or visible light radiation, in solution, can be broken down to free cyanide $\left(\mathrm{CN}^{-}\right.$and $\left.\mathrm{HCN}\right)$ [1]. Anthropogenic activities, like the process of gas purification after coal gasification in Manufactured Gas Plants (MGPs), yielded side products in the form of ferric ferrocyanide (Prussian Blue), leading possibly to the contamination of soil and groundwater. The manufactured gas was conducted through wood shavings, impregnated with hydrated iron

\footnotetext{
${ }^{*}$ Corresponding author.
}

oxide, in order to remove hydrogen sulfide $\left(\mathrm{H}_{2} \mathrm{~S}\right)$ and hydrogen cyanide $(\mathrm{HCN})$. When the iron oxide lost its absorbing capacity it was often deposited in the vicinities of MGP, which generated a potential environmental pollution due to high amounts of sulfur, tar and various complex iron-cyanides.

Knowledge concerning the behavior, particularly dissolution and desorption, of contaminants can help in reducing the extent of cleanup technologies. In order to design effective remediation strategies, it is relevant to understand contaminant fate and transport in soil, and to quantify and mathematically model the release rate [2]. The mobility of iron-cyanide complexes in soil is mainly 
governed by the characteristics of the soil solution $(\mathrm{pH}$, $\mathrm{pE})$, the presence of complexing cations $\left(\mathrm{K}^{+}, \mathrm{Mn}^{2+}, \mathrm{Fe}^{2+}\right.$, etc.), the presence of UV light as well as the substrate composition and stratigraphy (e.g. clay content, hydrological barriers) of the site. Fe-cyanide complexes are negatively charged and can form inner-sphere complexes on positively charged surfaces, which makes adsorption on the soil particles a possible $\mathrm{Fe}-\mathrm{CN}$ retention mechanism [3]. With decreasing $\mathrm{pH}$ the adsorption of ironcyanide complexes on iron and aluminum oxides surfaces, which are positively charged under acidic conditions, increases. Hence, neutral and alkaline soils sorb $\mathrm{CN}$ anions to a lower extent than acidic soils. Depending on the $\mathrm{pH}, \mathrm{Fe}-\mathrm{CN}$ complexes can be adsorbed on the soil organic matter (SOM). According to Mansfeldt [4], the adsorption takes place through hydrogen bonds under acidic conditions and through charge transfers complexes under neutral to caustic conditions. Fuller [5] stated that the sorption of ferricyanide in soil is driven by the $\mathrm{pH}$, iron-oxides and clay mineral content. According to Ohno [6] sorption of ferrocyanide was increased, when the $\mathrm{pH}$ of the soil decreased. Rennert and Mansfeldt [3] found that ferrocyanides adsorb on goethite surfaces rather than ferricyanides. Rennert and Mansfeldt [7] predicted that ferricyanide forms outer-sphere and weak inner-sphere surface complexes on goethite. According to them, ferrocyanide was sorbed inner-spherically and by precipitation of a Prussian Blue-like phase. Cheng and Huang [8] found that the adsorption of either ferrocyanide or ferricyanide complexes onto aluminum oxide is achieved through outersphere complexation. Ghosh et al. [9] carried out a column experiment, where both ferricyanide and ferrocyanide were not restrained by the sandy aquifer material.

Sorption of iron-cyanide complexes by soils, as shown above, is a subject that is studied in soil chemistry, but the reverse process (release/desorption) should be of an equal environmental interest, due to its practical importance. Column studies can provide key information concerning the mechanism of the iron-cyanide complexes dissolution or desorption. Release rate parameters can be estimated from the isotherms of the time dependent data using various mathematical models. The aim of this study was to use different isotherm and kinetic equations to investigate the phenomena of iron-cyanide complexes release from the MGP soils. Applying various models to the column experimental data, was believed to provide the knowledge whether the contaminant discharge is driven by the kinetics of desorption from the heterogeneous substrates (Elovich, Freundlich), the diffusioncontrolled phenomena (Parabolic Diffusion Equation) or by the transport following Multiple First Order Equation. Additionally the influence of soils parameters such as $\mathrm{pH}$, texture, $\mathrm{OM}$ content, initial $\mathrm{CN}$ concentrations on the iron-cyanide complexes release rate was studied.

\section{Materials and Methods}

\subsection{Field Data}

Field data on total and dissolved cyanide content of the soils, $\mathrm{pH}, \mathrm{EC}, \mathrm{OM}$ were obtained by sampling the site of aformer MGP in Cottbus $\left(51^{\circ} 45,161^{\prime} \mathrm{N} ; 14^{\circ} 18,529^{\prime} \mathrm{E}\right)$. The investigation field covers an area of $2500 \mathrm{~m}^{2}$ and is relatively flat. The annual average temperature is $8.8^{\circ} \mathrm{C}$ and average annual precipitation sum is $589 \mathrm{~mm}$ [10]. The local climate is characterized as humid continental [11]. Own pre-studies show that the groundwater table is situated at a depth about $7 \mathrm{~m}$ below the surface and the soil $\mathrm{pH}$ varies between 3.2 and 7.7 [12]. The top soil layer is composed of varying fractions of sand, coal, slag and organic matter (up to $0.5 \mathrm{~m}$ deep). The deeper soil $(0.5-2.0 \mathrm{~m})$ has a sandy texture (texture classes according to German classification system).

Gas works produced a variety of largely hazardous waste products (like iron-cyanide complexes) that were used as a filling material contaminating the surrounding field. Soils (labeled A, B, C and D) used in the column experiment originate from the former MGP site in Cottbus. Soils A, C and D are the top soils (up to $0.5 \mathrm{~m}$ deep), whereas soil B was the lower sandy layer $(0.5-1.5 \mathrm{~m}$ deep) of soil A. Selected chemical and physical properties of the investigated soils are presented in Table 1.

Grain size analysis was performed by sieving $(>20 \mu \mathrm{m})$ and X-ray granulometry (XRG) using the SediGraph $5120^{\mathrm{TM}}$ particle-size analyzer [13]. Organic matter was determined with the Loss on Ignition method (LOI). $\mathrm{pH}$ and EC were studied with a bench $\mathrm{pH} / \mathrm{mV}$ meter MultiLab 540 (WTW). Total and water soluble cyanide (Table 1) determination was performed according to the micro dist procedure US QuickChem Method 10-204-001-X [15]. After distillation cyanide was determined with the flow injection analyzer (FIA Compact, MLE) [16]. The detection limit for both (total and water soluble $\mathrm{CN}$ ) extractions is $0.02 \mathrm{mg} \cdot \mathrm{l}^{-1}$ of cyanide in analyte.

\subsection{Column Experiment (Dissolution/ Desorption)}

The release of iron-cyanide complexes from the MGP soils (A, B, C and D) was studied by conducting laboratory column experiments at constant flow rates under unsaturated conditions [14]. Eight percolation columns (two replicates for each soil) were constructed from Plexiglas $^{\circledR}$ (ID $5.4 \mathrm{~cm}$, height $30 \mathrm{~cm}$ ) and positioned perpendicular toeach other. A peristaltic pump fed distilled water to each column, in the beginning of the experiment at a flow rate of $20 \mathrm{ml} \cdot \mathrm{h}^{-1}$ once per day. Introduced soil was homogenized by hand and each column was loaded with $\approx 700 \mathrm{~g}$ of field fresh soil. The system was daily percolated with distilled water and the obtained 
Table 1. Selected chemical and physical properties of the investigated soils [14].

\begin{tabular}{|c|c|c|c|c|c|c|c|c|c|c|}
\hline \multirow[t]{2}{*}{ Soil } & \multirow[t]{2}{*}{ Soil characteristic } & $\mathrm{OM}$ & Water content & Tot. CN conc. & $\begin{array}{l}\text { Tot. water soluble } \\
\text { CN conc. }\end{array}$ & \multirow[t]{2}{*}{$\mathrm{pH}$} & $\mathrm{EC}$ & Clay & Silt & Sand \\
\hline & & $(\%)$ & $(\%)$ & $\left(\mathrm{mg} \cdot \mathrm{kg}^{-1}\right)$ & $\left(\mathrm{mg} \cdot \mathrm{kg}^{-1}\right)$ & & $\left(\mu \mathrm{S} \cdot \mathrm{cm}^{-1}\right)$ & $(\%)$ & $(\%)$ & $(\%)$ \\
\hline A & top soil & 3.4 & 12.6 & 875 & 148 & 7.6 & 1455 & 9.0 & 14.1 & 76.9 \\
\hline B & $0.5-1.5 \mathrm{~m}$ deep & 1.2 & 6.4 & 401 & 26 & 5.9 & 2041 & 11.8 & 17.6 & 70.6 \\
\hline $\mathrm{C}$ & top soil & 3.1 & 12.9 & 1718 & 21 & 5.0 & 2253 & 7.4 & 15.2 & 77.4 \\
\hline $\mathrm{D}$ & top soil & 4.2 & 10.6 & 40 & 0.6 & 7.7 & 780 & 8.0 & 14.1 & 77.9 \\
\hline
\end{tabular}

leachate was subsequently analyzed with the FIA. The experimental set up is shown in Figure 1.

\subsection{Isotherm Equations}

Three isotherm models were applied to the $\mathrm{CN}$ experimental data in order to better understand the release process of iron-cyanide complexes from the MGP soils with the varying $\mathrm{pH}, \mathrm{OM}$ content, $\mathrm{CN}$ concentration and soil texture. The gathered data were computed according to the following equations that often describe time-dependent data sufficiently [17].

\subsubsection{Elovich Equation [17]}

The Elovich equation is generally considered an empirical equation. It has been used in the soil chemistry to describe the kinetics of sorption and desorption of various inorganic materials on the soil [18], and the soil chemical reaction rates $[19,20]$.

$$
q=(1 / \alpha) \cdot \ln (a \cdot \alpha)+(1 / \alpha) \cdot \ln t
$$

where:

$q$ - the amount of released $\mathrm{CN}$ in time $t\left(\mathrm{mg} \cdot \mathrm{CN} \cdot \mathrm{kg}^{-1}\right)$;

$\alpha-$ a release constant $\left(\mathrm{mg} \cdot \mathrm{CN} \cdot \mathrm{kg}^{-1} \cdot \mathrm{day}^{-1}\right)$; and

$a-\mathrm{a}$ constant related to the initial velocity of the reaction $\left(\mathrm{mg} \cdot \mathrm{CN} \cdot \mathrm{kg}^{-1}\right)$.

Plot of " $q$ " vs. "In $t$ " gives a linear relationship with the slope of $(1 / \alpha)$ and the intercept of $(1 / \alpha), \ln (a \cdot \alpha)$.

\subsubsection{Parabolic Diffusion Equation [21]}

The parabolic diffusion equation is often used to indicate that diffusion-controlled phenomena are rate limited. The diffusion models have been developed to predict the dynamic character of release and have been successfully used to describe for example metal reactions on soil and soil constituents [22].

$$
q=a+K_{d} \cdot t^{1 / 2}
$$

where:

$q$ - the amount of released $\mathrm{CN}$ in time $t\left(\mathrm{mg} \cdot \mathrm{CN} \cdot \mathrm{kg}^{-1}\right)$;

$a$ - constant $\left(\mathrm{mg} \cdot \mathrm{CN} \cdot \mathrm{kg}^{-1}\right)$; and

$K_{d}$ - apparent diffusion rate constant

$\left(\mathrm{mg} \cdot \mathrm{CN} \cdot \mathrm{kg}^{-1} \cdot \mathrm{day}^{-1 / 2}\right)$.

Plot of " $q$ " vs. " $t$ "1/2" gives linear relationship if the reaction confirms the parabolic diffusion law. The " $a$ " and

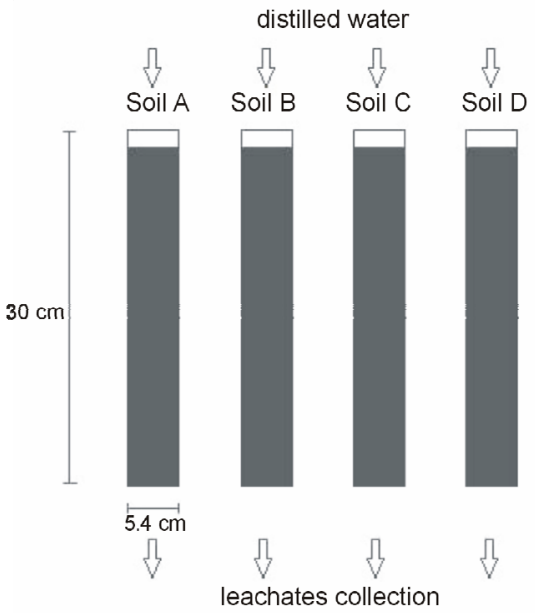

Figure 1. Scheme of the column experiment set-up.

" $K_{d}$ " parameters are determined from the intercept and the slope of the function respectively.

\subsubsection{Freundlich Equation [23]}

Freundlich equation is generally considered an empirical relationship describing the adsorption of solutes from a liquid to a solid surface, and have been widely applied to experimental data. Elkhatib et al. [24] used a modified Freundlich equation to describe the kinetics of lead and copper desorption [25] from soils.

$$
q=k \cdot t^{v}
$$

where:

$q$ - the amount of released $\mathrm{CN}$ in time $t\left(\mathrm{mg} \cdot \mathrm{CN} \cdot \mathrm{kg}^{-1}\right)$;

$k$-release rate coefficient $\left(\right.$ day $\left.^{-1}\right)$;

$t$-reaction time (day); and

$v$ - a constant.

The Freundlich isotherm is a power function, where " $k$ " and " $v$ " are constants that can be determined from the coefficient and the exponent respectively.

\subsection{Kinetic Equation}

Transport models assuming chemically controlled nonequilibrium, which describes the kinetic of a release or dissociation reactions is often defined as a first order reaction [26]. The heterogeneity of a system as well as the controlling mechanism of the release process (such as 
mass transfer or chemical reaction) determines the rate constants that are required to describe the experimental data.

\section{First Order Equation [27]}

Release kinetics based on the first order equation, where the total released amount $(q)$ within a certain time $(t)$, is expressed by the following equation:

$$
q=q_{0} \cdot\left(1-\mathrm{e}^{-k t}\right)
$$

where:

$q$ - the amount of released $\mathrm{CN}$ in time $t\left(\mathrm{mg} \cdot \mathrm{CN} \cdot \mathrm{kg}^{-1}\right)$;

$q_{0}$ - the amount of $\mathrm{CN}$ released at equilibrium

$\left(\mathrm{mg} \cdot \mathrm{CN} \cdot \mathrm{kg}^{-1}\right)$; and

$k$-apparent release rate coefficient $\left(\mathrm{day}^{-1}\right)$.

Assuming that $\mathrm{CN}$ release is constrained by more than one pool, total released $\mathrm{CN}$ amount should be expressed as:

$$
q_{\text {tot }}=q_{1}+q_{2}
$$

where:

$q_{\text {tot }}$-is the total amount of released CN in time $t$ $\left(\mathrm{mg} \cdot \mathrm{CN} \cdot \mathrm{kg}^{-1}\right)$;

$q_{1}$-is the fast releasing $\mathrm{CN}$ pool $\left(\mathrm{mg} \cdot \mathrm{CN} \cdot \mathrm{kg}^{-1}\right)$; and $q_{2}$-is the stronger fixed $\mathrm{CN}$ pool $\left(\mathrm{mg} \cdot \mathrm{CN} \cdot \mathrm{kg}^{-1}\right)$.

The release kinetics for two pools concept (one readily and one slowly liberating) can be expressed using the multiple first order rate equation, where each pool has its capacity and rate constant:

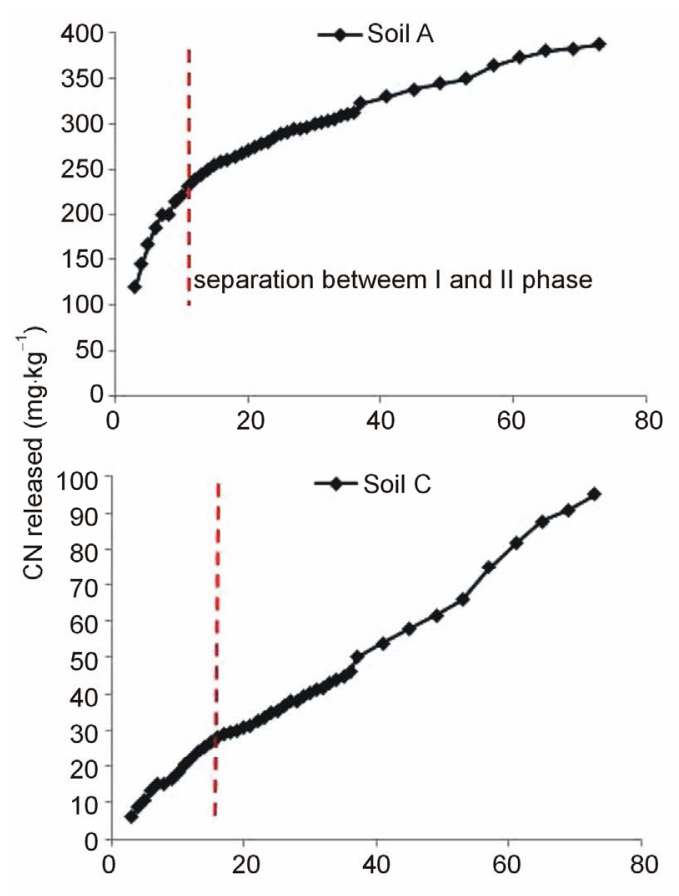
squares.
Release time (days)

$$
q=q_{1} \cdot\left(1-\mathrm{e}^{-k_{1} t}\right)+q_{2} \cdot\left(1-\mathrm{e}^{-k_{2} t}\right)
$$

Numerical parameters $(k)$ fit was based on least sum of

\subsection{Statistical Analysis}

The predictive performances of the developed models were assessed by adjusted correlation coefficient $\left(\mathrm{R}^{2}\right)$, standard error (SE) and the probability value (p), using the analysis of variance (ANOVA).

\section{Results}

\subsection{Column Experiment}

Release of cyanide from MGP soils (A, B, C and D), was investigated with the soil column experiment. The $\mathrm{CN}$ release rate was studied for four soils with different $\mathrm{pH}$ 's and textures (Table 1). According to Bodenkundliche Kartieranleitung [28], soil A and B are medium loamy sandsoils (SI3), whereas soils C and D are characterized as weak loamy sand soils (SI2). Figure 2 represents the relation of the released cyanide, plotted cumulatively, vs. release time. Figure 2 indicates that long-term $\mathrm{CN}$ release from soil can be described using two separate cyanide pools: one available and one strongly fixed. The amount of released cyanide representing each pool was visually obtained from the graph (Figure 2).

It is assumed that amount of cyanide in the column leachates is influenced by mobilization of readily soluble

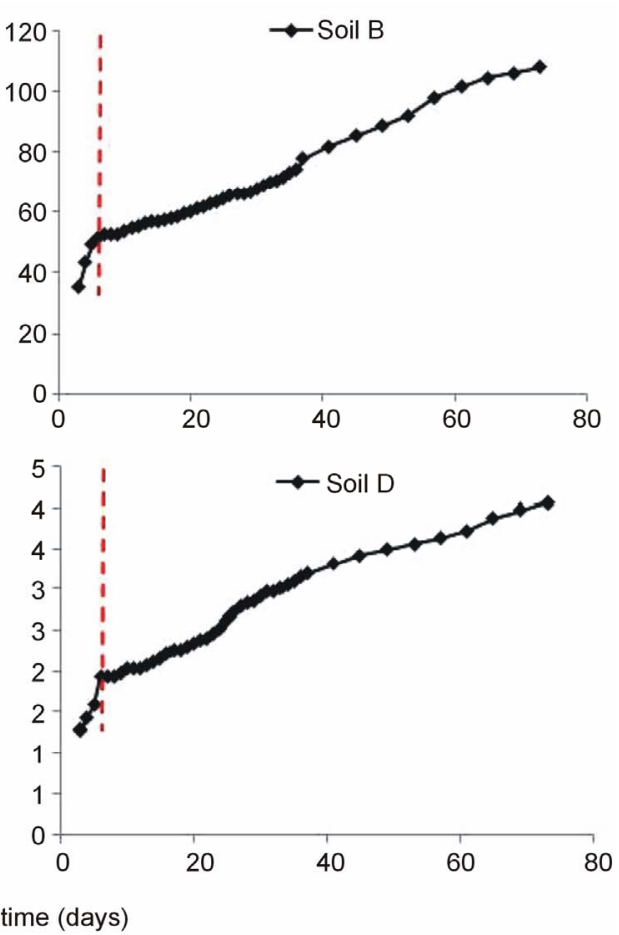

Figure 2. Cumulative $\mathrm{CN}$ release curves for the four investigated soils [14]. 
hexacyanoferrats (phase I) and slow dissolution of ferric ferrocyanide (phase II) [29]. The kinetics of $\mathrm{CN}$ release will be based on deriving a constant release rate for each phase, based on the continuously measured $\mathrm{CN}$ rerelease as a function of time.

\subsection{Isotherm Models}

Modeling of the $\mathrm{CN}$ release experimental data using isotherm equations assumes that the above mentioned two phase approach is separate in time and that phase I precedes phase II. Treating the processes separately, intent to derive the cyanide release rates for each phase.

\subsubsection{Elovich Equation}

The empirical equation [19] was used to describe the $\mathrm{CN}$ release rate from the MGP soils (A, B, C and D) in the column experiment. Figure 3 demonstrates the Elovich equation plots of released CN vs. In of reaction time obtained for phase I and phase II. In Figure 3 it can be noticed that a linear relationship exists between the released $\mathrm{CN}$ " $q$ " and ln of release time "In (release time)" for both phases in all investigated soils.

The Elovich equation parameters, determined from the slope and intercept of the linear plots, are given in Tables 2 and 3 . In the Elovich equation a decrease in " $\alpha$ " values and increase in " $a$ " values would increase the reaction rates [22]; [30]. Regression analysis (Table 2) indicated significant $(<0.01)$ correlation in all investigated soil.

The Elovich equation parameters for phase II are listed in Table 3. Regression analysis (Table 3) indicated significant $(<0.01)$ correlation in all investigated soils. As indicated by the regression analysis, the Elovich equation resulted to be adequate for describing the kinetics of $\mathrm{CN}$ release from contaminated soils in a column experiment. Moreover, the Elovich equation provides a very good fit $\left(\mathrm{R}^{2}>0.95\right)$ for phase I and a good fit $\left(\mathrm{R}^{2}>0.84\right)$ for phase II of $\mathrm{CN}$ release.

\subsubsection{Parabolic Diffusion}

The parabolic diffusion equation was subsequently used to describe the $\mathrm{CN}$ release from the contaminated soils (A, B, C and D) in the column experiment. A parabolic diffusion plot of $\mathrm{CN}$ release vs. $t^{1 / 2}$ is shown in Figure 4. The parabolic diffusion equation parameters, determined from the slope and intercept of the linear plots, are given in Tables $\mathbf{4}$ and $\mathbf{5}$.

Regression analysis for phase I (Table 4) indicated significant $(<0.01)$ correlation and high correlation coefficient $(>0.91)$ in all investigated soil. In phase II (Table 5), regression analysis demonstrates significant $(<0.01)$ correlation in all investigated soil, as well as high correlation coefficient $(>0.97)$ and low SE.
Table 2. The Elovich equation parameters and correlation coefficients for phase I CN release in the MGP soils.

\begin{tabular}{cccccc}
\hline & \multicolumn{5}{c}{ Phase I } \\
\cline { 2 - 5 } Soil & $\alpha$ & $a$ & & & \\
& \multicolumn{7}{c}{$a$} & $\mathrm{SE}$ & $\mathrm{p}$ \\
\cline { 2 - 5 } & $\mathrm{mg} \cdot \mathrm{CN} \cdot \mathrm{kg}^{-1} \cdot \mathrm{day}^{-1}$ & $\mathrm{mg} \cdot \mathrm{CN} \cdot \mathrm{kg}^{-1}$ & & & \\
\hline $\mathrm{A}$ & 0.01 & 125.00 & 0.99 & 3.29 & $<0.01$ \\
B & 0.05 & 39.92 & 0.96 & 1.54 & $<0.01$ \\
$\mathrm{C}$ & 0.07 & 5.82 & 0.98 & 1.37 & $<0.01$ \\
$\mathrm{D}$ & 2.02 & 2.21 & 0.98 & 0.03 & $<0.01$ \\
\hline
\end{tabular}

Table 3. The Elovich equation parameters and correlation coefficients for phase II CN release in the MGP soils.

\begin{tabular}{|c|c|c|c|c|c|}
\hline \multirow{3}{*}{ Soil } & \multicolumn{5}{|c|}{ Phase II } \\
\hline & $\alpha$ & $a$ & \multirow{2}{*}{$\mathrm{R}^{2}$} & \multirow{2}{*}{$\mathrm{SE}$} & \multirow{2}{*}{$\mathrm{p}$} \\
\hline & $\mathrm{mg} \cdot \mathrm{CN} \cdot \mathrm{kg}^{-1} \cdot$ day $^{-1}$ & $\mathrm{mg} \cdot \mathrm{CN} \cdot \mathrm{kg}^{-1}$ & & & \\
\hline A & 0.01 & 88.99 & 0.98 & 4.46 & $<0.01$ \\
\hline B & 0.04 & 15.77 & 0.85 & 5.72 & $<0.01$ \\
\hline $\mathrm{C}$ & 0.02 & 3.79 & 0.96 & 3.81 & $<0.01$ \\
\hline D & 1.27 & 0.58 & 0.93 & 0.08 & $<0.01$ \\
\hline
\end{tabular}

Table 4. The parabolic diffusion equation parameters and correlation coefficients for phase I CN release in the MGP soils.

\begin{tabular}{|c|c|c|c|c|c|}
\hline \multirow{3}{*}{ Soil } & \multicolumn{5}{|c|}{ Phase I } \\
\hline & $K_{d}$ & $a$ & $D^{2}$ & & \\
\hline & $\mathrm{mg} \cdot \mathrm{CN} \cdot \mathrm{kg}^{-1} \cdot \mathrm{day}^{-1 / 2}$ & $\mathrm{mg} \cdot \mathrm{CN} \cdot \mathrm{kg}^{-1}$ & 内 & SL & $\mathrm{p}$ \\
\hline A & 83.00 & 69.63 & 0.94 & 4.96 & $<0.01$ \\
\hline B & 32.18 & 35.81 & 0.99 & 0.81 & $<0.01$ \\
\hline $\mathrm{C}$ & 10.03 & 5.57 & 0.99 & 0.77 & $<0.01$ \\
\hline D & 0.54 & 0.02 & 0.92 & 0.11 & $<0.01$ \\
\hline
\end{tabular}

Table 5. The parabolic diffusion equation parameters and correlation coefficients for phase II CN release in the MGP soils.

\begin{tabular}{cccccc}
\hline & \multicolumn{5}{c}{ Phase II } \\
\cline { 2 - 4 } Soil & $K_{d}$ & $a$ & & & \\
\cline { 2 - 5 } & $\mathrm{mg} \cdot \mathrm{CN} \cdot \mathrm{kg}^{-1} \cdot \mathrm{day}^{-1 / 2}$ & $\mathrm{mg} \cdot \mathrm{CN} \cdot \mathrm{kg}^{-1}$ & & & $\mathrm{p} E$ \\
\hline $\mathrm{A}$ & 29.30 & 139.92 & 0.99 & 2.26 & $<0.01$ \\
B & 10.29 & 15.98 & 0.94 & 3.60 & $<0.01$ \\
$\mathrm{C}$ & 17.12 & 53.96 & 0.98 & 2.60 & $<0.01$ \\
$\mathrm{D}$ & 0.26 & 0.95 & 0.97 & 0.05 & $<0.01$ \\
\hline
\end{tabular}

\subsubsection{Freundlich Equation}

The Freundlich equation was also used to describe the CN release from the MGP soils in a column experiment. The Freundlich isotherm is a power function, where " $v$ " and " $k$ " are constants. Isotherms of this form have been 


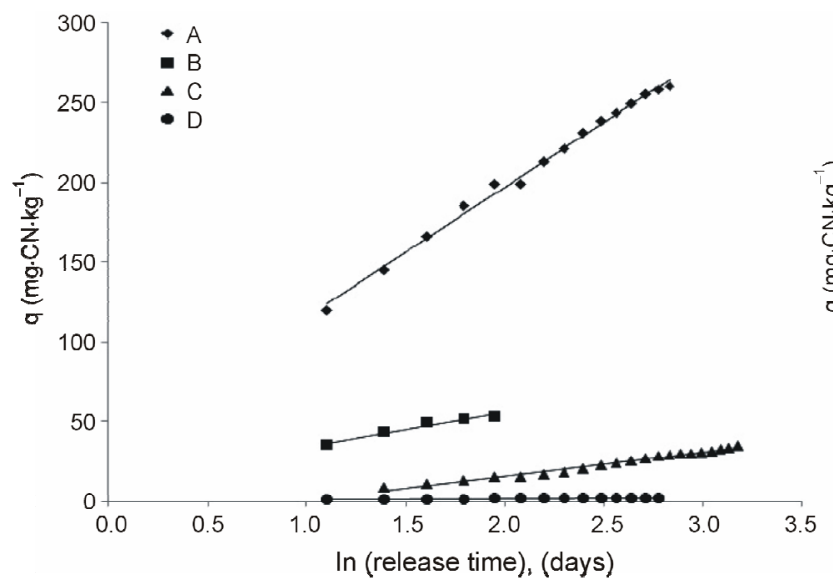

(a)

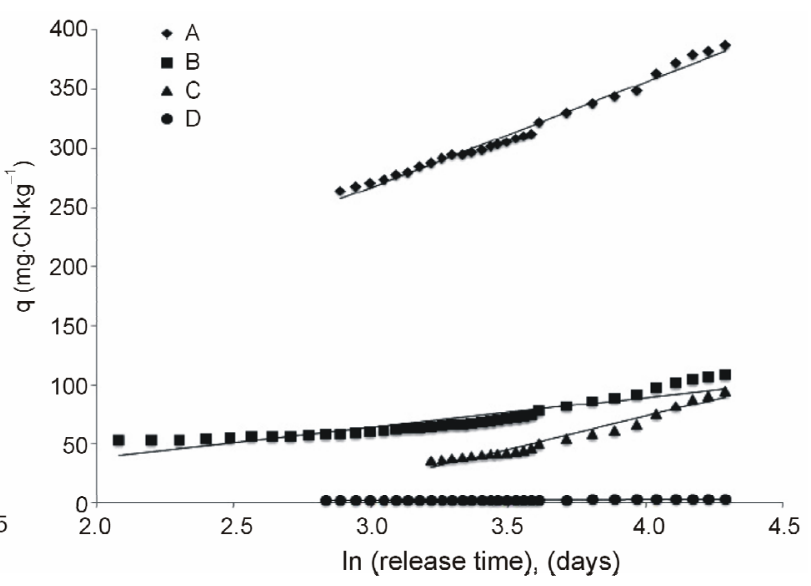

(b)

Figure 3. The Elovich equation plots for CN release from the MGP soils in (a) phase I and (b) phase II.

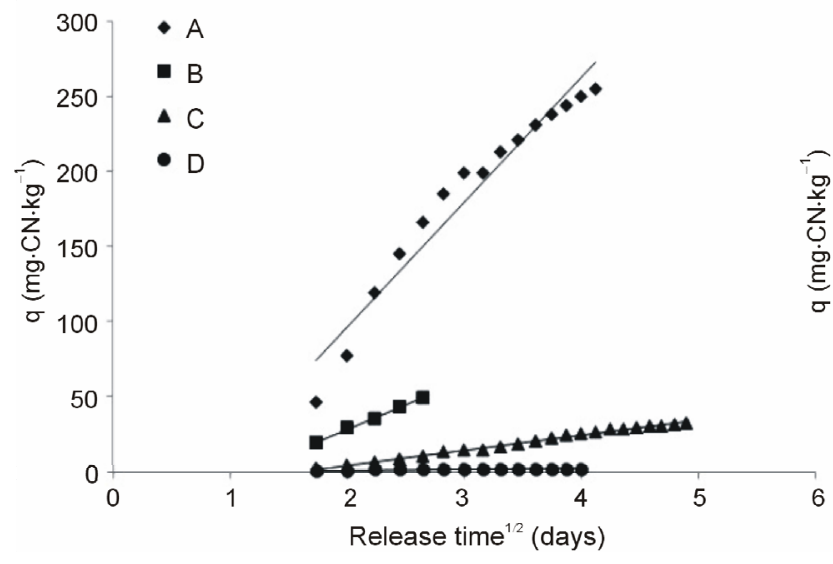

(a)

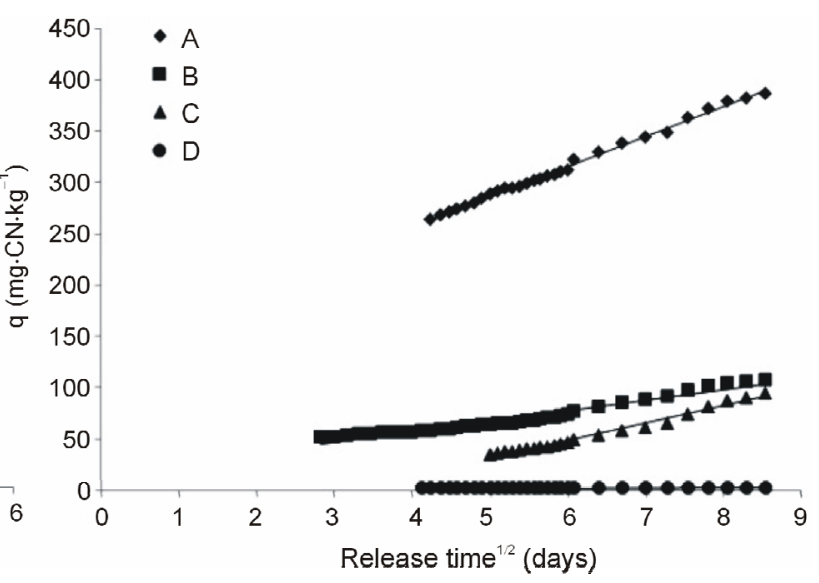

(b)

Figure 4. The parabolic diffusion equation plots for CN release from the MGP soils in (a) phase I and (b) phase II.

observed for a wide range of heterogeneous surfaces, including activated carbon, silica, clays, metals, and polymers [31]. The release of $\mathrm{CN}$ in phase I and II was well modeled by the Freundlich equation (Figure 5).

In both phases (I and II), a power function was able to fit the data with a high degree of correlation: $\mathrm{R}^{2}>0.93$ and $\mathrm{R}^{2}>0.90$ respectively. Regression analysis (Tables 6 and 7) indicated significant $(<0.01)$ correlation in all investigated soil. The Freundlich equation proved to be successful in describing both phases in $\mathrm{CN}$ release from the MGP soils.

\subsection{Kinetic Model}

Another consideration assumes that release of iron-cyanide complexes is constrained by two phases that occur simultaneously, which would suggest non-equilibrium liberation. In this approach transport phenomena of phase I is not considered separately from the slow chemical reaction of phase II. For this approach, a modified first order equation was used. The total released $\mathrm{CN}$ amount
Table 6. The Freundlich equation parameters and correlation coefficients for phase I CN release in the MGP soils.

\begin{tabular}{|c|c|c|c|c|c|}
\hline \multirow{3}{*}{ Soil } & \multicolumn{5}{|c|}{ Phase I } \\
\hline & \multirow{2}{*}{$v \times 10^{-3}$} & $k$ & \multirow{2}{*}{$\mathrm{R}^{2}$} & \multirow{2}{*}{ SE } & \multirow{2}{*}{$\mathrm{p}$} \\
\hline & & day $^{-1}$ & & & \\
\hline A & 427.60 & 81.40 & 0.97 & 7.30 & $<0.01$ \\
\hline B & 477.30 & 21.77 & 0.94 & 2.00 & $<0.01$ \\
\hline $\mathrm{C}$ & 596.50 & 5.58 & 0.98 & 0.70 & $<0.01$ \\
\hline D & 295.40 & 0.94 & 0.97 & 0.04 & $<0.01$ \\
\hline
\end{tabular}

Table 7. Freundlich equation parameters and correlation coefficients for phase II CN release in the MGP soils.

\begin{tabular}{cccccc}
\hline & \multicolumn{5}{c}{ Phase II } \\
\cline { 2 - 5 } Soil & $v \times 10^{-3}$ & \multicolumn{1}{c}{$k$} & $\mathrm{R}^{2}$ & $\mathrm{SE}$ & $\mathrm{p}$ \\
\cline { 2 - 3 } & & $\mathrm{day}^{-1}$ & & & \\
\hline A & 278.40 & 117.00 & 0.99 & 3.60 & $<0.01$ \\
B & 345.90 & 22.37 & 0.91 & 3.80 & $<0.01$ \\
C & 948.70 & 1.60 & 0.99 & 2.70 & $<0.01$ \\
D & 300.30 & 0.87 & 0.95 & 0.06 & $<0.01$ \\
\hline
\end{tabular}


was determined as a sum of phase I and phase II (Equation 6), where each phase had its capacity and rate constant.

\section{Multiple First Order Equation}

A multiple, two-component first-order equation was used to describe the $\mathrm{CN}$ release form the MGP soils in a column experiment. Figure 6 represents fitted release curves for the investigated soils, the measured $\mathrm{CN}$ and the released quantities form both phases. Figure 6 shows that the two-component first order model provides a good fit of the experimental data for soil A, B and D. The multiple first order equation parameters and correlation coefficients are listed in Table 8. Applying this kinetic approach, it was assumed that each phase has its release rate $(k)$, which is proportional to the amount present in a specific pool.

Regression analysis (Table 8) indicated significant $(<0.01)$ correlation in all investigated soil. According to the correlation coefficient and standard error, a modified two-component first-order equation was successful in describing the experimental data from soil A, B and D. Slightly worse correlation was obtained for soil $\mathrm{C}\left(\mathrm{R}^{2}=\right.$ $0.89 ; \mathrm{SE}=7.42$ ).

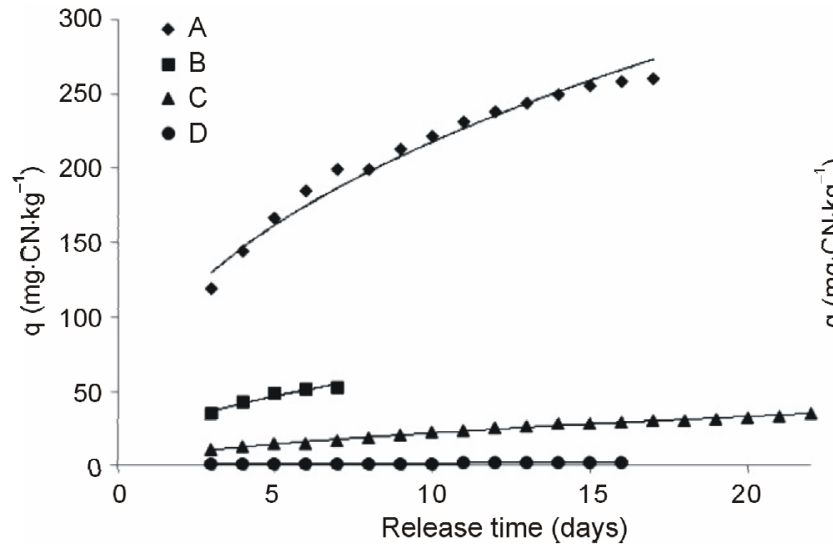

(a)

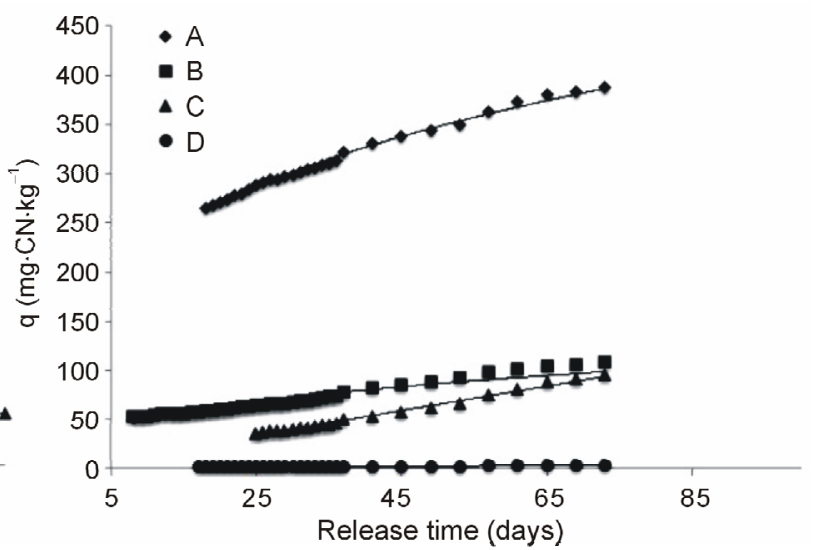

(b)

Figure 5. The Freundlich equation plots for CN release from the MGP soils in (a) phase I and (b) phase II.

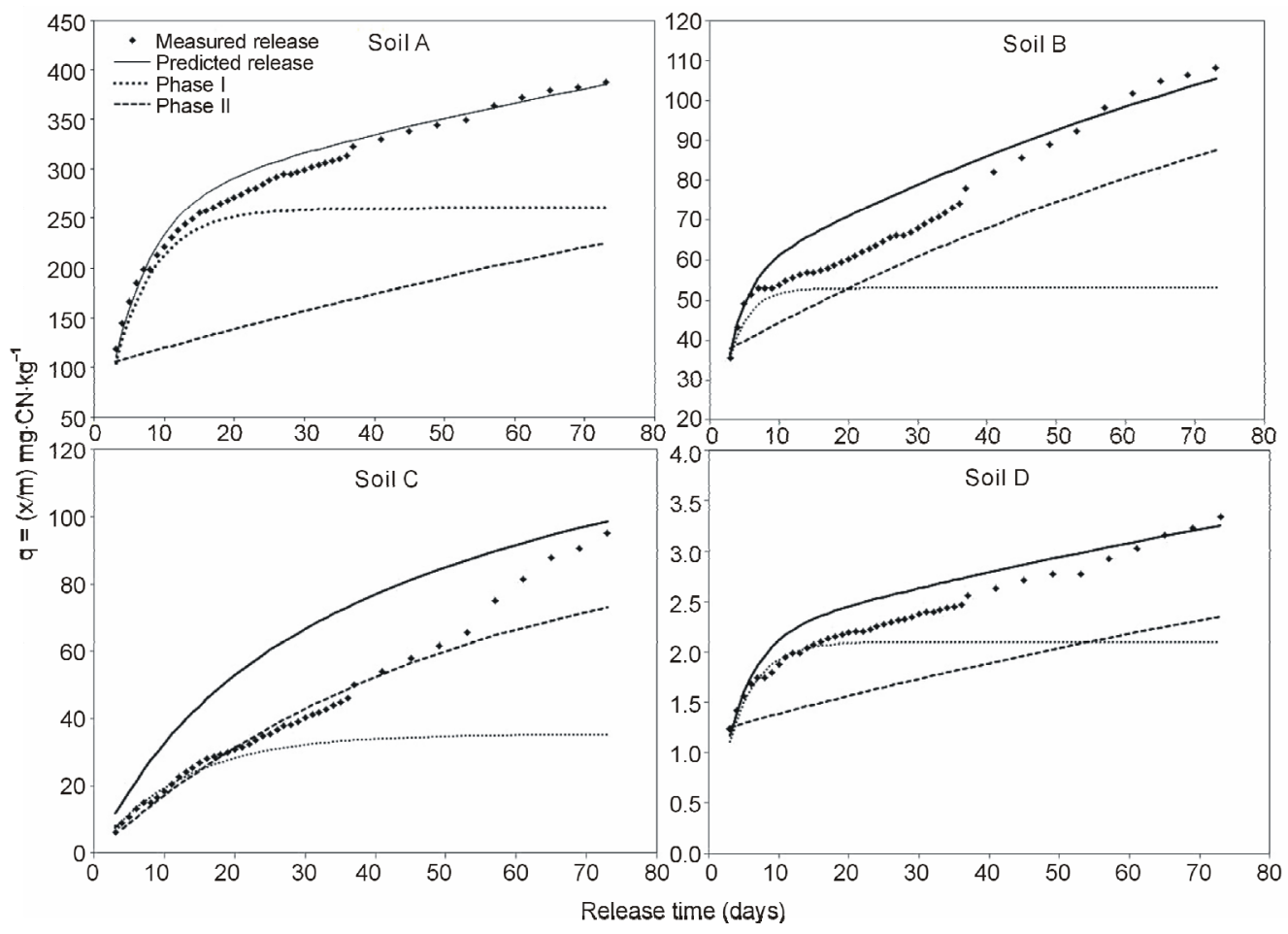

Figure 6. Cumulative measured CN release plots with predicted CN release, phase I and phase II, using the modified first order equation, for the MGP soils. 
Table 8. The multiple first order equation parameters and correlation coefficients for $\mathrm{CN}$ release in the MGP soils.

\begin{tabular}{ccccccc}
\hline & Phase I & Phase II & & & \\
\cline { 2 - 3 } Soil & $k_{1}$ & $k_{2}$ & $\mathrm{R}^{2}$ & $\mathrm{SE}$ & $\mathrm{p}$ \\
\cline { 2 - 3 } & $\mathrm{day}^{-1}$ & day $^{-1}$ & & & \\
\hline A & 0.17 & $0.53 \times 10^{-2}$ & 0.97 & 9.28 & $<0.01$ \\
B & 0.37 & 0.01 & & 0.92 & 4.14 & $<0.01$ \\
C & 0.08 & 0.01 & & 0.89 & 7.42 & $<0.01$ \\
D & $0.5 \times 10^{-2}$ & 0.25 & & 0.94 & 0.10 & $<0.01$ \\
\hline
\end{tabular}

\section{Discussion}

In contaminated soils, on the sites of former MGPs, the mobility of iron-cyanide complexes is mainly governed by the dissolution and precipitation of ferric ferrocyanide and adsorption on soil minerals [32]. The purpose of our work was to gain better knowledge concerning the ironcyanide complexes release from the MGP soils by applying various isotherm and kinetic equations. The column experiment simulated the experimental conditions relevant to anthropogenically altered soils. The approach presented here assumes that the release of iron-cyanide complexes is constrained by two phases. According to Aharoni et al. [23], the rate of release is rapid, when it is governed by the transport process taking place in the liquid phase, or diffusion in the bulk of the liquid, at the film adjacent to the solid particle, in liquid-filled pores, etc. Theis et al. [33] attributed quick and complete desorption of ferricyanide from goethite to outer-sphere complexation.

If the release rate is slow, it is probably limited by the process taking place in the solid phase. It can be constrained by the constant dissolution of the ferric ferrocyanide like precipitate, which according to Mansfeldt and Dohrmann [34] may originate from coprecipitation on the soil surface or from precipitation of iron-cyanide complexes with alkali and alkaline earth cations. Rennert and Mansfeldt [7]; [35] proposed that slow and incomeplete desorption of ferrocyanide was attributed to inner-sphere surface complexation, which occurs through the formation of direct chemical bonds with the mineral surface, (typically with surface oxygen atoms), and by precipitation of a Prussian Blue-like phase on the goethite surface.

Pursuant to the results obtained in the column experiment (Figure 2), it is believed that the release of ironcyanide complexes from the contaminated soils can be described using two separate cyanide pools: one available (like transport of readily dissolved hexacyanoferrats or desorption of weak outer-sphere complexation) and one strongly fixed (like dissolution of precipitate in from of ferric ferrocyanide or desorption of inner-sphere complexation). Applying the isotherm models to the column experimental data required handling the phases separately in order to derive the release rate constants. Implementing the equations to the complete data set (Figure 2) resulted in very low correlations, which proves the hypothesis that the release of iron-cyanide complexes from the MGP soils is constrained by two phases.

The Elovich equation has been frequently used to study the chemical release processes and is suitable for systems with heterogeneous adsorbing surfaces [36]. The kinetic behavior of inorganic materials like metals $(\mathrm{Pb}$ and $\mathrm{Cu}$ ) has been successfully described by the Elovich equation [22]; [23]. Mathematical analysis of the $\mathrm{CN}$ release data indicated that the Elovich equation is suitable to describe the kinetic behavior of iron-cyanide complexes in the MGP soils (Figure 3). In the Elovich equation, a decrease in " $\alpha$ " increases the reaction rate. In phase I (Table 2), the $\mathrm{CN}$ release rate increases with the increasing soil $\mathrm{pH}$ (Table 1), except for the soil D, where release rate is very low according to soil $\mathrm{pH}$ (7.7). The low release rate of soil $\mathrm{D}$ is most probably caused by the low total $\mathrm{CN}$ concentration (Table 1) hence, the cyanide release rate in phase I is influenced by the soil $\mathrm{pH}$ as well as the initial $\mathrm{CN}$ concentration in soil. Generally, in the desorption processes, one of the most important parameter is the initial $\mathrm{pH}$ value of the solution, which influences both the contaminant surface binding sites and the contaminant chemistry in water. Our findings are consistent with the study made by Ohno [6], who investigated sorption of ferrocyanide by five soils, where increasing sorption was observed with decreasing soil $\mathrm{pH}$. In phase II, the relation of " $\alpha$ " and " $a$ " values are analogous with the ones obtained for phase I, where the release rates for phase I are higher than for phase II. Low $\mathrm{pH}$ of the soil C $(\mathrm{pH}=5)$ most probably reduces the amount of readily dissolved iron-cyanide complexes in the phase I, which results in only slightly higher " $\alpha$ " values for the phase II. Lower, but still significant, was the correlation in soil B $\left(\mathrm{R}^{2}=0.85\right)$, which may be affected by the low OM content (Table 1). On the other hand, depending on $\mathrm{pH}$, the overall charge of SOM is either neutral or negative, hence the anion adsorption cannot be expected. However, Rennert and Mansfeltd [3] state that SOM promotes the sorption, hence the content of $\mathrm{C}_{\text {org }}$ is possibly enhancing the sorption of iron-cyanide complexes on soils. The suggested reaction for this process was the charge transfer complexes, formed by cyanide ion $\left(\mathrm{CN}^{-}\right)$, via cyanide-N with quinone groups of humic acids [37].

Simultaneously, the parabolic diffusion equation was used to describe the CN release from the MGP soils. This model has been used by many scientists to characterize the diffusion-controlled phenomena in soil constituents and the release of ion in soil and soil minerals [38]. It assumes that described $\mathrm{CN}$ release is determined by the sum of various diffusion processes with different diffu- 
sion coefficients and various particle sizes. Linear relationship visible in phase II indicates (Figure 4) that the parabolic equation adequately describes the $\mathrm{CN}$ release process, suggesting that phase II is driven by the diffusion of $\mathrm{CN}$ out of the mineral matrix. On the other hand, in phase I, the regression line for the soil A doesn't pass through the origin, suggesting that the diffusion is not the main driving mechanisms. Additionally, in phase I, the " $a$ " value was determined from the y-intercept $(t=0)$. The intercept is most probably affected by the rapid $\mathrm{CN}$ release, which would be much slower if not influenced by the transport of already dissolved phase. The apparent CN diffusion rate coefficient " $K_{d}$ " in the parabolic diffusion law is considered the measure of the relative rate of $\mathrm{CN}$ release [23]. The difference between the " $K_{d}$ " values indicates that the release power of the soils is different. In phase I (Table 4), the " $K_{d}$ " values for the studied soils were increasing with the increasing soil $\mathrm{pH}$, except for the soil $\mathrm{D}$, which despite of the alkaline character, indicated low $\mathrm{CN}$ release, most probably induced by low initial CN concentration. Soil B, despite of acidic character, indicated comparably high $\mathrm{CN}$ release rate, which can be attributed to the low OM content. The diffusion coefficient " $K_{d}$ " is higher in sandy soils with lower organic matter. More heterogenic soils are more likely to have an increase in transport-limited process [23]. In phase II, the relative rate of $\mathrm{CN}$ release $\left(K_{d}\right)$ seems to be affected by the $\mathrm{CN}$ concentration. Major decrease in " $K_{d}$ " value can be noticed in soil $\mathrm{A}$, despite of basic soil $\mathrm{pH}$. Release rate in soil B also decreased, whereas in soil C, continuous release, comparable to the one obtained in phase I, can be observed (Table 5). Based on correlation coefficient it can be stated that the parabolic diffusion law effectively describes the phase II of $\mathrm{CN}$ release from the MGP soils. For the phase I, the results revealed (" $a$ " value determined from the y-intercept) that the diffusion phenomena is not the driving mechanisms, however it doesn't imply that $\mathrm{CN}$ release does not include a slow diffusion reaction. It may rather indicate that the kinetics of this process shouldn't be considered separately from the transport phenomena. More study need to be done to determine whether $\mathrm{CN}$ release is driven by intraparticle diffusion, external-film diffusion or internal-pore diffusion.

Subsequently, the release of $\mathrm{CN}$ from the MGP soil was described using the Freundlich equation. This power function exhibits increasing release rate with increasing time, but decreasing positive slope as time increases (Figure 5). The Freundlich equation is often used for heterogeneous surfaces and describes desorption from solid to the solutes in liquid and assumes that different sites with several adsorption energies are involved. Many organics and inorganics follow this type of behavior [19]; [23]. According to mathematical analysis (Tables 6 and
7), the Freundlich reaction based model was successful in describing, both phase I and phase II, CN release from the MGP soils. The exception is phase I in soil A, where the regression line doesn't pass through the origin (Figure 5), suggesting that desorption is not the driving mechanism. Soil A is alkaline $(\mathrm{pH}=7.6)$ and has high $\mathrm{CN}$ content, which would explain high amount of dissolved cyanide in the pore water and imply that the $\mathrm{CN}$ release in phase I is mainly constrained by the transport of readily dissolved compounds rather than desorption. The values of release rate coefficient " $k$ ", in phase I and II, decrease with the decreasing soil $\mathrm{pH}$, except for the soil $\mathrm{D}$, where low " $k$ " value might be a result of low $\mathrm{CN}$ concentration in soil.

Applying the isotherm equations to the column data was aimed at better understanding the mechanisms of the $\mathrm{CN}$ release that, prior to the kinetic study, was divided in two phases. This modeling approach assumed that phase I and phase II are separated in time. Results revealed various release rates in both phases, implying that the driving mechanisms are different. The column experimental data for phase II showed good correlation with the Elovich, Freundlich and Parabolic Diffusion Equations leading to inconclusive results about the driving mechanisms of the $\mathrm{CN}$ release. For the phase I, poor fitting of the regression line (Freundlich) and the negative intercept values (Parabolic diffusion), implied the transport of dissolved iron-cyanide complexes as the main process.

The First order equation was previously used by many researchers to describe time-dependent data [26]; [39]. This modeling approach assumes that both $\mathrm{CN}$ release phases occur simultaneously. The modified first order model well described the $\mathrm{CN}$ release data (Table 8), which is supported by the graphical test presented in Figure 6. This result suggests that the release of $\mathrm{CN}$ from the MGP soils followed the multiple first order kinetics. Worst graphical and regressional correlation was obtained for soil $\mathrm{C}$. The release of $\mathrm{CN}$ from soil $\mathrm{C}$ is almost linear, most probably due to low soil $\mathrm{pH}$, constrained mainly by one strongly fixed pool. According to Meeussen et al. [40] the mobility of cyanide in the soil largely depends on $\mathrm{pH}$. Under acidic conditions, solid iron-cyanide complexes in the form of precipitated Prussian Blue are likely to be expected. It could explain why the two-component approach didn't manage to describe the kinetics of $\mathrm{CN}$ release from the soil C. Due to the low $\mathrm{pH}$, the amount of dissolved iron-cyanide complexes is relatively low, so the difference in the release rates for phase I and phase II is relatively small (Table 8).

Rate constants for each soil vary (Table 8), indicating the highest release rate in soil B for phase I and in soil D for phase II. The low initial release rate in phase I for soil $\mathrm{C}$ is consistent with the study made by Meeussen et al. 
[40]. They stated that acidic character of soil will considerably decrease the $\mathrm{CN}$ concentration in groundwater and reduce the mobility of iron-cyanide complexes in such soils. High initial release rate $\left(k_{1}\right)$ in soil B can be constrained by the low OM content, despite of a slightly acidic character of the soil. Using the multiple first order kinetic equation for modeling of the long-term cyanide release probably closer reflects the phenomena that occur in the MGP soils. It is more probable that the release of phase I and phase II appear simultaneously rather than completely separate in time.

\section{Conclusions}

The study of iron-cyanide complex release, in a column experiment, was conducted to investigate the long-term desorption or dissolution mechanisms. The research revealed that the cyanide liberation from the investigated MGP soils is driven by two phases. From the kinetic studies, it was observed that the cyanide release was initially rapid (phase I) followed by a much slower release rate (phase II). Most probably, one more fraction exists (an amount that is not released), but our experimental time scale didn't allow for that observation.

Modeling with isotherm equations, assuming that both phases are separate in time, delivered inconclusive results concerning the driving mechanisms for the cyanide release in phase II. The Elovich equation was in good agreement to describe the $\mathrm{CN}$ release in phase I and II, suggesting desorption from the heterogeneous surfaces to the liquid. Analogously good correlation was obtained by using the Freundlich equation, except for phase I in soil $\mathrm{A}$, where too high $\mathrm{CN}$ content and alkaline $\mathrm{pH}$ imply transport of readily dissolved cyanide as a main driving release mechanism. The parabolic diffusion adequately describes the rate-limiting $\mathrm{CN}$ release (phase II), implying that it's driven by the diffusion of $\mathrm{CN}$ out of the mineral matrix. For phase I, obtained results imply that transport of dissolved cyanide is the main mechanisms. Indefinite results for phase II, obtained from applying the isotherm equations, most probably indicate that the long-term iron cyanide release from the MGP soils is a complex phenomenon driven by various mechanisms parallely involving desorption, diffusion and dissolution processes.

The multiple first order equation assumed simultaneous occurrence of both phases and adequately described the $\mathrm{CN}$ release from soil $\mathrm{A}, \mathrm{B}$ and $\mathrm{D}$, except for the soil $\mathrm{C}$, where due to it's acidic character, the $\mathrm{CN}$ mobility is most probably constrained by one strongly fixed pool. This non-equilibrium approach is considered to closer reflect the probable cyanide release mechanisms from the MGP soils.

Based on conducted isotherm and kinetic modeling, we attribute the fast release rate (phase I) to the transport process of readily dissolved iron-cyanide complexes (hexacyanoferrats) that is taking place in the liquid phase combined with the desorption of $\mathrm{CN}$ bound to heterogeneous surfaces that are in direct contact with aqueous phase (outer-sphere complexation).

Mobility governed on the low release level (phase II) is probably controlled by the desorption, dissolution or diffusion processes, like the dissolution of precipitated ferric ferrocyanide or of inner-sphere complexed ferricyanides.

The iron-cyanide release rates for phase I and II, obtained in the kinetic modeling, revealed that the $\mathrm{CN}$ mobility is mainly influenced by the $\mathrm{pH}$ (which affects both the contaminant surface binding sites and the contaminant chemistry in water), by the initial $\mathrm{CN}$ concentration and by the possible sorption on soil organic matter. The cyanide release rates increased with the increasing $\mathrm{pH}$, decreased with low initial $\mathrm{CN}$ concentration and was retarded by the increase in $\mathrm{OM}$ content.

\section{Acknowledgements}

This work was supported by the Brandenburg Ministry of Science, Research and Culture (MWFK) as part of the International Graduate School (IGS) at Brandenburg University of Technology (BTU). This study was partially funded by Deutsche Bahn AG within the project "Stabilisierung des DB AG-Standortes ehem. Leuchtgasanstalt Cottbus durch Verfahren der Bioremediation (Phytoremediation)".

\section{REFERENCES}

[1] P. Kjeldsen, "Behavior of Cyanides in Soil and Groundwater: A Review," Water, Air \& Soil Pollution, Vol. 115 , No. 1-4, 1998, pp. 279-307.

http://dx.doi.org/10.1023/A:1005145324157

[2] C. M. Saffron, J. H. Park, B. E. Dale and T. C. Voice, "Kinetics of Contaminant Desorption Form Soil: Comparison of Model Formulations Using the Akaika Information Criterion," Environmental Science Technology, Vol. 40, 2006, pp. 7662-7667. http://dx.doi.org/10.1021/es0603610

[3] T. Rennert and T. Mansfeldt, "Sorption of Iron-Cyanide Complexes in Soil," Soils Science Society of American Journal, Vol. 66, No. 2, 2002, pp. 437-444. http://dx.doi.org/10.2136/sssaj2002.0437

[4] T. Mansfeldt, "Mobilität und Mobilisierbarkeit von Eisenkomplexierten Cyaniden. Materialien zur Altlastensanierung und zum Bodenschutz (MALBO)," Landesumweltamt Nordrhein-Westfalen (LUA NRW), Vol. 16, 2003, pp. 17-44.

[5] W. H. Fuller, "Cyanides in the Environment with Particular Attention to the Soil," In: D. Van Zyl, Ed., Cyanide and the Environment, Colorado State University, Fort Collins, 1985, pp. 19-44.

[6] T. Ohno, "Levels of Total Cyanide and $\mathrm{NaCl}$ in Surface 
Waters Adjacent to Road Salt Storage Facilities," Environmental Pollution, Vol. 67, No. 2, 1990, pp. 123-132. http://dx.doi.org/10.1016/0269-7491(90)90077-P

[7] T. Rennert and T. Mansfeldt, "Sorption of Iron-Cyanide Complexes on Goethite," European Journal of Soil Science, Vol. 52, No. 1, 2001, pp. 121-128.

http://dx.doi.org/10.1046/j.1365-2389.2001.t01-1-00368.x

[8] W. P. Cheng and C. Huang, "Adsorption Characteristics of Iron-Cyanide Complex on $\gamma-\mathrm{Al}_{2} \mathrm{O}_{3}$," Journal of Colloid Interface Science, Vol. 181, No. 2, 1996, pp. 627-637. http://dx.doi.org/10.1006/jcis.1996.0420

[9] R. S. Ghosh, D. A. Dzombak, R. G. Luthy and D. V. Nakles, "Subsurface Fate and Transport of Cyanide Species at a Manufactured Gas Plant Site," Water Environment Research, Vol. 71, No. 6, 1999, pp. 1205-1216. http://dx.doi.org/10.2175/106143096X122474

[10] M. Linder, H. Bugmann, P. Lasch, M. Fleschig and W. Cramer, "Regional Impacts of Climatic Change on Forests in the State of Brandenburg, Germany," Agricultural and Forest Meteorology, Vol. 84, No. 1-2, 1997, pp. 123-135. http://dx.doi.org/10.1016/S0168-1923(96)02381-7

[11] M. C. Peel, B. L. Finlayson and T. A. McMahon, "Updated World Map of the Köppen Geiger Climate Classification," Hydrology and Earth System Sciences, Vol. 11, 2007, pp. 1633-1644.

http://dx.doi.org/10.5194/hess-11-1633-2007

[12] M. Sut, T. Fischer, F. Repmann, T. Raab and T. Dimitrova, "Feasibility of Field Portable Near Infrared (NIR) Spectroscopy to Determine Cyanide Concentrations in Soil," Water, Air \& Soil Pollution, Vol. 223, No. 8, 2012, pp. 5495-5504. http://dx.doi.org/10.1007/s11270-012-1298-y

[13] H. W. Müller, R. Dohrmann, D. Klosa, S. Rehder and W. Eckelmann, "Comparison of Two Procedures for ParticleSize Analysis: Köhn Pipette and X-Ray Granulometry," Journal of Plant Nutrition and Soil science, Vol. 172, No. 2, 2009, pp. 172-179. http://dx.doi.org/10.1002/jpln.200800065

[14] M. Sut, F. Repmann and T. Raab, "Stability of Prussian Blue in Soils of a Former Manufactured Gas Plant Site," Soil and Sediments Contamination an International Journal. http://dx.doi.org/10.1080/15320383.2014.839626

[15] USEPA, "Method 10-204-00-1-X, Lachat US EPA Approved and Equivalent Method," Revision 3, 2008.

[16] DIN EN ISO 14 403, "Bestimmung von Gesamt Cyanid und Freiem Cyanid mit Derkontinuerlichen Fließanalytik-Teil D,” 2002.

[17] S. H. Chien, W. R. Clayton and G. H. McClellan, "Kinetics of Dissolution of Phosphate Rocks in Soil," Soils Science Society of American Journal, Vol. 44, No. 2, 1980, pp. 260-264.

http://dx.doi.org/10.2136/sssaj1980.03615995004400020 $\underline{012 \mathrm{x}}$

[18] R. J. Atkinson, F. J. Hingston, A. M. Posner and J. P. Quirk, "Elovich Equation for the Kinetics of Isotope Exchange Reaction at Soild-Liquid Interfaces," Nature, Vol. 226, 1970, pp. 148-149.

http://dx.doi.org/10.1038/226148a0
[19] S. H. Chien and W. R. Clayton, "Application of Elovich Equation to the Kinetics of Phosphate Release and Sorption in Soils," Soils Science Society of American Journal, Vol. 44, No. 2, 1980, pp. 265-268.

http://dx.doi.org/10.2136/sssaj1980.03615995004400020 $\underline{013 \mathrm{x}}$

[20] J. Torrent, "Rapid and Slow Phosphate Sorption by Mediterranean Soils. Effect of Iron Oxides," Soils Science Society of American Journal, Vol. 51, 1987, pp. 78-82.

[21] K. J. Laidler, "Chemical Kinetics," McGraw-Hill, New York, 1965.

[22] P. M. Jardine and D. L. Sparks, "Potassium-Calcium Exchange in Multireactive Soil System. I. Kinetics," Soils Science Society of American Journal, Vol. 48, No. 1, 1984, pp. 39-45.

http://dx.doi.org/10.2136/sssaj1984.03615995004800010 $\underline{007 x}$

[23] C. Aharoni, D. L. Sparks, S. Levinson and I. Ravina, "Kinetics of Soil Chemical Reactions: Relationships between Empirical Equations and Diffusion Models," Soils Science Society of American Journal, Vol. 55, 1991, pp. 1307-1312.

http://dx.doi.org/10.2136/sssaj1991.03615995005500050 $\underline{019 \mathrm{x}}$

[24] E. A. Elkhatib, G. M. ElShebiny and A. M. Balba, "Comparison of Four Equations to Describe the Kinetics of Lead Desorption from Soils," Zeitschrift für Pflanzenernährung und Bodenkunde, Vol. 155, 1992, pp. 285-291. http://dx.doi.org/10.1002/jpln.19921550408

[25] E. A. Elkhatib, A. M. Mahdy, M. E. Saleh and N. H. Barakat, "Kinetics of Copper Desorption from Soils as Affected by Different Organic Ligands," International Journal of Envirnomental Science Technology, Vol. 4, No. 3, 2007, pp. 331-338.

[26] M. M. Nederlof, W. H. Van Riemsdijk and L. K. Koopal, "Analysis of the Rate of Dissociation of Ligand Complexes," Environmental Science and Technology, Vol. 28, 1994, pp. 1048-1053. http://dx.doi.org/10.1021/es00055a013

[27] S. E. A. T. M. Van der Zee and W. H. Van Riemsdijk, "Model for Long-Term Phosphate Reaction Kinetics in Soil," Journal of Environmental Quality, Vol. 17, No. 1, 1998, pp. 35-41.

http://dx.doi.org/10.2134/jeq1988.00472425001700010005x

[28] Bodenkundliche Kartieranleitung, AG Boden, 5. Aufl., 438 S., 41 Abb., 103 Tab., 31 Listen, Hannover, 2005.

[29] F. J. Hingston, A. M. Posner and J. P. Quirk, "Anion Adsorption by Goethite and Gibbsite. II. Desorption of Anions from Hydrous Oxide Surfaces," Journal of Soil Sciences, Vol. 25, No. 1, 1974, pp. 16-26. http://dx.doi.org/10.1111/j.1365-2389.1974.tb01098.x

[30] M. J. D. Low, "Kinetics of Chemisorption of Gases on Solids," Chemical Reviews, Vol. 60, No. 3, 1960, pp. 267-312. http://dx.doi.org/10.1021/cr60205a003

[31] R. J. Umpleby II, S. C. Baxter, M. Bode, J. K. Berch Jr., R. N. Shah and K. D. Shimizu, "Application of the Freundlich Adsorption Isotherm in the Characterization of Molecularly Imprinted Polymers," Analitica Chimica Acta, 
Vol. 435, No. 1, 2001, pp. 35-42. http://dx.doi.org/10.1016/S0003-2670(00)01211-3

[32] J. L. Meeussen, M. G. Keizer, W. H. Van Riemsdijk and F. A. M. de Haan, "Dissolution Behavior of Iron Cyanide (Prussian Blue) in Contaminated Soils," Environmental Science \& Technology, Vol. 26, No. 9, 1992, pp. 18321838. http://dx.doi.org/10.1021/es00033a019

[33] T. L. Theis and M. L. West, "Effects of Cyanide Complexation on the Adsorption of Trace Metals at the Surface of Goethite," Environmental Technology Letters, Vol. 7, No. 1-12, 1986, pp. 309-318. http://dx.doi.org/10.1080/09593338609384417

[34] T. Mansfeldt and R. Dohrmann, "Identification of a Crystalline Cyanide-Containing Compound in Blast Furnace Sludge Deposits," Journal of Environmental Quality, Vol. 30, No. 6, 2001, pp. 1927-1932. http://dx.doi.org/10.2134/jeq2001.1927

[35] T. Rennert and T. Mansfeldt, "Sorption of Iron-Cyanide Complexes on Goethite in the Presence of Sulfate and Desorption with Phosphate and Chloride," Journal of Environmental Quality, Vol. 31, No. 3, 2002, pp. 745-751. http://dx.doi.org/10.2134/jeq2002.0745

[36] F. C. Wu, R. L. Tseng and R. S. Juang, "Characteristics of Elovich Equation Used for the Analysis of Adsorption
Kinetics in Dye-Chitosan Systems," Chemical Engineering Journal, Vol. 150, 2009, pp. 366-373. http://dx.doi.org/10.1016/j.cej.2009.01.014

[37] B. Schenk and B. M. Wilke, "Cyanidadsorption an Sesquioxiden, Tonmineralen und Huminstoffen," Zeitschrift für Pflanzenernährung und Bodenkunde, Vol. 147, No. 6, 1984, pp. 669-679. http://dx.doi.org/10.1002/jpln.19841470604

[38] R. L. Evans and J. J. Jurinak, "Kinetics of Phosphate Release from a Desert Soil," Soil Science, Vol. 121, No. 4, 1976, pp. 205-211. http://dx.doi.org/10.1097/00010694-197604000-00003

[39] D. Freese, "Criteria and Methods for the Assessment of Long-Term Phosphate Sorption and Desorption in Soils," Habilitationsschrift, Landwirtschaftlich-Gärtnerischen Fakultät, Humboldt-Universität zu Berlin, 1994.

[40] J. C. Meeussen, G. Meindert, W. H. Van Riemsdijk and F. A. M. de Haan, "Solubility of Cyanide in Contaminated Soils," Journal of Environmental Quality, Vol. 23, No. 4, 1994, pp. 785-787. http://dx.doi.org/10.2134/jeq1994.0047242500230004002 $\underline{4 x}$ 